\title{
Carbon Dioxide Enrichment of High-value Crops under Tunnel Culture
}

\author{
T.K. Hartz, A. Baameur', and D.B. Holt \\ Department of Botany and Plant Sciences, University of California, Riverside, CA 92521 \\ Additional index words. Cucumis sativus, Cucurbita pepo, Lycopersicon esculentum, Fragaria $\times$ ananassa
}

\begin{abstract}
The feasibility of field-scale $\mathrm{CO}_{2}$ enrichment of vegetable crops grown under tunnel culture was studied with cucumber (Cucumis saivus L. Cv. Dasher II), summer squash (Cucurbita pepo L. Cv. Gold Bar), and tomato (Lycopersicon escukntum Mill. cv. Bingo) grown under polyethylene tunnels. The drip irrigation system was used to uniformly deliver a $\mathrm{CO}_{2}$-enriched air stream independent of irrigation. Carbon dioxide was maintained between 700 and $1000 \mu \mathrm{l} \cdot \mathrm{liter}^{-1}$ during daylight hours. Enrichment began immediately after crop establishment and continued for $\approx 4$ weeks. At the end of the treatment phase, enrichment had significantly increased plant dry weight in the 2 years of tests. This growth advantage continued through harvest, with enriched cucumber, squash, and tomato plots yielding $30 \%, 20 \%$, and $32 \%$ more fruit, respectively, in 1989. In 1990, cucumber and squash yields were increased $20 \%$, and $16 \%$, respectively. As performed, the expense of $\mathrm{CO}_{2}$ enrichment represented less than a $10 \%$ increase in total preharvest costs. A similar test was conducted on fall-planted strawberries (Fragaria $\times$ ananassa Duch. Cvs. Irvine and Chandler). Carbon dioxide enrichment under tunnel culture modestly increased 'Irvine' yields but did not affect 'Chandler'.
\end{abstract}

Carbon dioxide enrichment of greenhouse crops has been a standard commercial practice for many years. Vegetable crops such as tomato, cucumber, and lettuce respond positively to greenhouse enrichment; yield increases of $20 \%$ to $40 \%$ are common (Hadley and Livermore, 1989; Kimball, 1986; Peet and Willits, 1987; Slack, 1986). Carbon dioxide enrichment for such crops under field conditions has been the subject of considerable speculation. The concept has generally been dismissed as impractical due to problems in uniformity of distribution and rapid dispersal of applied $\mathrm{CO}_{2}$ by wind movement.

The use of polyethylene-covered growing tunnels has in recent years become a relatively common cultural practice for the production of high-value crops; the substantial cost of this technique can be offset by increased yield and a market premium for earlier production. The use of polyethylene tunnels provides a relatively static atmosphere around the crop, improving the practicality of $\mathrm{CO}_{2}$ enrichment on a field basis. Hadley and Livermore (1989) reported increased growth rate and earlier maturity of crisphead lettuce (Lactuca sativa L.) when small, air-inflated field enclosures were enriched to approximately three times normal atmospheric $\mathrm{CO}_{2}$ concentration. The applicability of their study was limited in that their enclosures were in essence small greenhouses, and their $\mathrm{CO}_{2}$ distribution system consisted of delivering pure $\mathrm{CO}_{2}$ though a perforated plastic pipe.

A more practical solution to the issue of even distribution would be to deliver $\mathrm{CO}_{2}$ through drip irrigation lines (Wittwer, 1979). Wittwer's idea was to deliver $\mathrm{CO}_{2}$ in the irrigation water stream. Nakayama and Bucks (1980) documented crop response under field conditions with this technique, although plant response probably was not due directly to enhancement of atmospheric $\mathrm{CO}_{2}$ concentration; root-zone delivery of $\mathrm{CO}_{2}$ has been shown to induce effects beyond enhancement of photosynthesis (Arteca et al., 1979; Govindarajan and Poovaiah, 1982; Mauney and Hendrix, 1988). Carbon dioxide delivery in irrigation water is of limited usefulness for atmospheric enrichment, since ideal timing and application amount for each are

Received for publication 19 Nov. 1990. The cost of publishing this paper was defrayed in part by the payment of page charges. Under postal regulations, this paper therefore must be hereby marked advertisement solely to indicate this fact.

Univ. of California Cooperative Extension, Riverside. not compatible. However, using a drip irrigation system for delivery of gaseous $\mathrm{CO}_{2}$ independent of water application could be a workable field technique.

This study was undertaken to document agronomic response and economic feasibility of $\mathrm{CO}_{2}$ enrichment of high-value crops grown under conventional polyethylene tunnels, using drip irrigation lines as the distribution system for $\mathrm{CO}_{2}$.

\section{Materials and Methods}

Field studies were conducted during Spring 1989 and 1990 at the Univ. of California Agricultural Experiment Station at Riverside, and during Fall 1989 at the Univ. of California South Coast Field Station in Irvine. Soils were Buren fine sandy loam (Riverside) and San Emigdio sandy loam (Irvine). In Spring 1989, the Riverside site was fumigated with a methyl bromide/ chloropicrin mixture. A broadcast application of $55 \mathrm{~kg} \mathrm{~N}$ and $30 \mathrm{~kg} \mathrm{P}$ was made before the formation of raised beds on 1.5$\mathrm{m}$ centers. A single drip irrigation line (Turbo-tape, 20-cm emitter spacing, T-Systems, San Diego, Calif.) was buried $10 \mathrm{~cm}$ deep in the center of each bed.

A $\mathrm{CO}_{2}$ injection system was constructed that used the buried drip irrigation lines to deliver a $\mathrm{CO}_{2}$-enriched air stream uniformly down the length of each row. The system contained a vacuum motor whose positive pressure port provided an air flow at $\approx 7 \mathrm{kPa}$ static pressure. Bottled $\mathrm{CO}_{2}$ was metered and blended into this flow to provide enrichment to a concentration of $\approx 5 \%$ $\mathrm{v} / \mathrm{v}$. The rate of delivery of the enriched air, $\approx 0.3$ liter $\cdot \mathrm{min}^{-1} \cdot \mathrm{m}^{-1}$ drip tape, was sufficiently slow to allow adequate mixing of this potentially toxic $\mathrm{CO}_{2}$ concentration with the tunnel atmosphere.

The $\mathrm{CO}_{2}$ level in the enriched tunnel atmosphere was monitored by a nondispersive infrared $\mathrm{CO}_{2}$ analyzer originally designed for greenhouse use (Model 2044, Valtronics, Concord, Calif.). The monitor's switching capabilities operated the delivery system, delivering enrichment when tunnel atmsophere $\mathrm{CO}_{2}$ concentration fell below $700 \mu \mathrm{l} \cdot \mathrm{liter}^{-1}$, stopping flow at 1000 $\mu 1 \cdot$ liter $^{-1}$. A sampling manifold was constructed that drew a composite air sample from three enriched tunnels $15 \mathrm{~cm}$ above the soil surface. The overall control of the system, which operated on 110-VAC current, was a time clock that limited hours of operation to 0800 to $1500 \mathrm{HR}$. The delivery of enriched air was accomplished independently of irrigation, which was ap- 
plied as needed after the daily enrichment period. We also periodically monitored $\mathrm{CO}_{2}$ concentration in nonenriched tunnels. The analyzer was recalibrated twice during the enrichment period using standardized gas mixtures.

On 1 Mar. 1989, the experimental area was planted with seed of 'Dasher II' cucumber and 'Gold Bar' squash. Conventional growing tunnels were constructed over the seeded rows; the tunnels consisted of wire hoops covered by single sheets of 30 $\mu \mathrm{m}$ clear, perforated polyethylene. The perforations, which comprised $1 \%$ of the surface area, were needed to prevent lethal temperature buildup should unseasonably warm weather occur. As configured in this study, the tunnels had a cross-sectional area of $0.3 \mathrm{~m}^{2}$. On 10 Mar., 4-week-old 'Bingo' tomato transplants were planted and covered by tunnels. The design for each crop was a randomized complete block, with five replications. Individual plots were $10 \mathrm{~m}$ (cucumber, squash) or $6 \mathrm{~m}$ (tomato) long. In-row plant spacing was $30 \mathrm{~cm}$ (cucumber) or $45 \mathrm{~cm}$ (tomato, squash). The $\mathrm{CO}_{2}$-enrichment treatment began on 13 Mar., at which time the seeded crops were at the first true-leaf stage, and continued until 7 Apr., when hot weather forced ventilation of the tunnels.

Upon termination of the enrichment, two representative plants from each cucumber and squash plot were harvested and ovendried at $65 \mathrm{C}$ for dry weight determination. Routine cultural practices were followed for the balance of the cropping season. Cucumbers were harvested eight times from 21 Apr.-18 May, squash five times from 1-29 May. Breaker-stage tomatoes were harvested 16 and 26 June, followed by a harvest of all remaining fruit on 3 July.

This study was repeated at Riverside during Spring 1990. The protocol was the same as previously described with the following modifications. The drip irrigation lines through which the $\mathrm{CO}_{2}$-enriched air stream was delivered were placed on the soil surface rather than underground. A different $\mathrm{CO}_{2}$ monitor was used (Model APBA-250E, Horiba Instruments, Irvine.) Metamsodium at 230 liters a.i./ha applied preplant in irrigation water provided weed control. The design was a randomized complete block with four 6-m plots.

Cucumber and squash (same cultivars as 1989) were seeded on 27 Feb. and immediately covered with tunnels. Carbon dioxide enrichment began 20 Mar., at the two true-leaf stage. Enrichment was applied daily, as previously described, until 12 Apr. (squash) and 20 Apr. (cucumber), the earlier termination on the squash necessitated by its larger size and the restricted area within the tunnel. Plant dry weights were again taken at the termination of enrichment. Yields were taken weekly on both crops from 3-24 May.

This tunnel enrichment procedure was also evaluated on fallplanted strawberries at Irvine in 1989. Raised soil beds on 1.7$\mathrm{m}$ centers were prepared and fertilized by banded application of $70 \mathrm{~kg} \mathrm{~N}$ and $40 \mathrm{~kg} \mathrm{P} / \mathrm{ha}$. The beds were mulched with $30 \mu \mathrm{m}$ clear polyethylene. Metam-sodium at 230 liters a.i./ha was applied in water through buried drip irrigation lines to control weeds and soil-borne pathogens. Crowns of 'Irvine' and 'Chandler' strawberries were planted in a four-row-per-bed configuration at a density of $100,000 /$ ha on 19 Oct. The design for each cultivar was a randomized complete block with four replications. Individual plots contained 50 plants. Since the use of tunnels is not an established practice for Southern California strawberry production, a conventional (nonenriched, nontunneled) control was included in addition to the nonenriched tunnel control.

After a 3-week establishment period, polyethylene tunnels were constructed. Carbon dioxide enrichment began on 14 Nov., with delivery through drip lines on the soil surface. Enrichment was delivered from 0800 to $1600 \mathrm{HR}$ daily, as previously described. With the exception of two windy periods when enrichment was suspended, the treatment continued until $20 \mathrm{Dec}$. for 'Irvine' and Jan. 1990 for 'Chandler'. Termination of enrichment corresponded to the initiation of harvest of the cultivars.

Upon termination of enrichment, tunnels were removed and routine commercial management practices instituted. Additional $\mathrm{N}$ was applied weekly at $12 \mathrm{~kg} \cdot \mathrm{ha}^{-1}$ through drip injection. Weekly harvests were taken until 15 May 1990.

\section{Results and Discussion}

The $\mathrm{CO}_{2}$ injection system worked well under calm conditions, maintaining $\mathrm{CO}_{2}$ in the target range. However, in wind velocities $>5 \mathrm{~m} \cdot \mathrm{s}^{-1}$, the delivery system maintained $700 \mu \mathrm{l} \cdot$ liter- $^{1}$ with difficulty. Enrichment was halted on several occasions due to extreme winds. The perforated tunnels allowed sufficient air exchange to maintain $\mathrm{CO}_{2}$ concentration in nonenriched tunnels near ambient levels. Tunnel air temperatures were substantially higher in 1989, with a daily maximum of 41C compared with $37 \mathrm{C}$ in 1990

Enrichment of the tunnel atmosphere increased plant dry weight of cucumber $57 \%$ and $32 \%$, and squash $69 \%$ and $70 \%$ for 1989 and 1990, respectively (Table 1). At the end of the treatment period, $\mathrm{CO}_{2}$-enriched plants appeared to be more vigorous; cucumber plants were also more advanced with respect to bloom and fruit set. Enriched tomato and strawberry plants also showed enhanced growth, but plant dry weights were not determined.

Carbon dioxide enrichment significantly increased total marketable yield of cucumber and squash in both years, with the magnitude of increase greater in 1989 (Table 1). There were no differences in cucumber quality between treatments. Field labor constraints restricted squash harvests to weekly intervals, so many fruit were larger than commercially desirable; the only quality classification of squash was marketability, irrespective of fruit size. Tomato also showed significantly enhanced productivity, with enrichment increasing marketable yield by $32 \%$ (Table 2). Mean fruit size also was increased.

Enrichment resulted in earlier cucumber harvest, with harvest of enriched plots beginning 5 to 7 days before nonenriched plots in both years. Differences in early yield, defined as yield in the

Table 1. Effect of $\mathrm{CO}_{2}$ enrichment on cucumber and squash production.

\begin{tabular}{|c|c|c|c|c|c|}
\hline \multirow[b]{2}{*}{ Crop } & \multirow[b]{2}{*}{ Year } & \multirow[b]{2}{*}{ Treatment } & \multirow{2}{*}{$\begin{array}{c}\text { Plant dry } \\
\text { wt } \\
\text { (g) }\end{array}$} & \multicolumn{2}{|c|}{$\begin{array}{c}\text { Marketable } \\
\text { yield } \\
(\mathrm{kg} / \mathrm{plot})\end{array}$} \\
\hline & & & & Early & Total \\
\hline Cucumber & 1989 & $\begin{array}{l}\text { Enriched tunnel } \\
\text { Tunnel control }\end{array}$ & $\begin{array}{c}22.3 \\
14.2 \\
*\end{array}$ & $\begin{array}{c}12.59 \\
4.87 \\
* *\end{array}$ & $\begin{array}{c}46.9 \\
36.1 \\
* *\end{array}$ \\
\hline & 1990 & $\begin{array}{l}\text { Enriched tunnel } \\
\text { Tunnel control }\end{array}$ & $\begin{array}{c}31.2 \\
23.5 \\
*\end{array}$ & $\begin{array}{c}11.45 \\
8.74 \\
\text { NS }\end{array}$ & $\begin{array}{c}29.3 \\
24.5 \\
*\end{array}$ \\
\hline Squash & 1989 & $\begin{array}{l}\text { Enriched tunnel } \\
\text { Tunnel control }\end{array}$ & $\begin{array}{c}70.2 \\
41.6 \\
*\end{array}$ & $\begin{array}{l}5.38 \\
5.45 \\
\text { NS }\end{array}$ & $\begin{array}{c}51.0 \\
42.6 \\
* *\end{array}$ \\
\hline & 1990 & $\begin{array}{l}\text { Enriched tunnel } \\
\text { Tunnel control }\end{array}$ & $\begin{array}{l}31.3 \\
18.4\end{array}$ & $\begin{array}{l}5.84 \\
4.31\end{array}$ & $\begin{array}{l}29.8 \\
25.8\end{array}$ \\
\hline & & & $*$ & NS & $*$ \\
\hline
\end{tabular}
tively. 
Table 2. Effect of $\mathrm{CO}_{2}$ enrichment on tomato production under tunnels, 1989.

\begin{tabular}{|c|c|c|c|c|c|}
\hline \multirow[b]{3}{*}{ Enrichment } & \multirow{2}{*}{\multicolumn{2}{|c|}{$\begin{array}{c}\text { Marketable } \\
\text { yield } \\
(\mathrm{kg} / \mathrm{plot}) \\
\end{array}$}} & \multicolumn{3}{|c|}{$\begin{array}{c}\text { Fruit size } \\
\text { distribution }(\%)\end{array}$} \\
\hline & & & \multicolumn{3}{|c|}{$\mathrm{D}$ i a m } \\
\hline & Early & $\mathrm{T}$ o t a 1 & $<7$ & $5 \mathrm{c} \mathrm{m}$ & $>7.5 \mathrm{~cm}$ \\
\hline Yes & 11.46 & 64.0 & & 23 & 77 \\
\hline No & 12.91 & 47.9 & & 35 & 65 \\
\hline
\end{tabular}

ss, Nonsignificant or significant at $P=0.05$.

Table 3. Effect of tunnel culture and $\mathrm{CO}_{2}$ enrichment on strawberry production.

\begin{tabular}{llc}
\hline \hline & \multicolumn{2}{c}{$\begin{array}{c}\text { Marketable yield } \\
(\mathrm{kg} / \mathrm{plot})\end{array}$} \\
\cline { 2 - 3 } Treatment & Irvine & Chandler \\
\hline Enriched tunnel (ET) & 27.3 & 32.8 \\
Tunnel control (TC) & 25.9 & 29.1 \\
Conventional control (CC) & 24.4 & 31.1 \\
Orthogonal comparisons & & \\
Significance & & 0.09 \\
ET vs. TC & 0.06 & $\mathrm{~N} \mathrm{~S}$ \\
ET vs. CC & 0.01 & \\
\hline
\end{tabular}

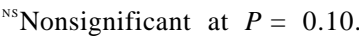

first half of the harvest period, was significant only in 1989. Extremely high tunnel temperatures in 1989 (maximum >45C) caused abortion of early fruits in squash and tomato, delaying harvest and obscuring treatment effects on earliness. In 1990, enrichment had a negliglble effect on earliness in squash.

Both strawberry cultivars showed a marginal yield increase due to enrichment compared with the tunnel, nonenriched treatment (Table 3). Compared with conventionally grown (nontunnel) plants, enrichment under tunnel culture significantly improved productivity of 'Irvine', but not of 'Chandler'. Mean fruit size was unaffected by treatment $(\approx 19 \mathrm{~g}$ for 'Irvine', $\approx 17 \mathrm{~g}$ for 'Chandler'). Enrichment enhanced yield for the first 4 weeks of the harvest season for both cultivars, but these early harvests accounted for $<5 \%$ of seasonal total yield.

Carbon dioxide usage amounted to $\approx 115$ and $95 \mathrm{~kg} \cdot \mathrm{ha}^{-1} \cdot \mathrm{day}^{-1}$ for the Spring 1989 and 1990 tests, respectively. Daily usage was considerably higher for the strawberry test, $170 \mathrm{~kg} \cdot \mathrm{ha}^{-1}$, reflecting longer hours of operation and more wind-induced loss.

Enrichment of cucurbits and tomato resulted in growth enhancement and yield increases similar to those reported in greenhouse enrichment studies. In reviewing numerous previous studies, Kimball (1986) found a mean yield increase of $26 \%$ for cucumber due to $\mathrm{CO}_{2}$ enrichment. Calvert and Slack (1975) reported a similar response in greenhouse-grown tomato. The advanced maturity of enriched cucumber plots was also consistent with reports on other crops (Goldsberry, 1988; Hadley and Livermore, 1989; Milhet and Costes, 1975).

The major difference between traditional greenhouse-enrichment regimes and the current study is that greenhouse enrichment typically" takes place throughout the cropping season, whereas "the tunnel enrichment was confined to early season growth. The success of tunnel enrichment as conducted here may be partially attributable to enrichment throughout the day; greenhouse enrichment is often interrupted by venting for temperature control. Slack (1986) reported that maximum benefit occurs when enrichment is applied for long periods without interruption.
In cucumber and squash, there were considerable differences in overall productivity and response to enrichment between years. Slower plant development and lower yields in 1990 may have been related to cooler seasonal temperatures and less-effective soil fumigation than in 1989.

Another difference of potential importance was the placement of the drip irrigation lines, which were buried in 1989 and on the soil surface in 1990. Root-zone application of $\mathrm{CO}_{2}$ has been shown to have significant stimulator effects on a diversity of crops, including Citrus (Labanauskas, et al., 1971), cotton (Gos.ypium hirwdum L.) (Mauney and Hendrix, 1988), eggplant (Solanum melongena L.) (Baron and Gorski, 1986), potato (Solanum tuberosum L.) (Arteca et al, 1979) and wheat (Triticum aestivum L.) (Nakayama and Bucks, 1980). Beyond actual root fixation of soil-applied $\mathrm{CO}_{2}$ (Arteca and Poovaiah, 1982; Baron and Gorski,. 1986) other mechanisms of action have been suggested, including inhibition of ethylene biosynthesis and action (Govindarajan and Poovaiah, 1982) and alteration of endogenous hormone levels (Arteca et al., 1980). The stronger response to enrichment in 1989 may have been related to one or more of these factors acting in concert with atmospheric enrichment.

Despite obvious stimulation of early season plant growth, the effects of tunnel culture and enrichment on strawberry production were nominal. This marginal response may be related to the complex physiology of flowering in strawberry; daylength, temperature, varietal characteristics, environment of crown production, etc. all influence the timing and number of flower buds initiated. The use of tunnels, as deployed in this study, radically increased air temperature, which may have modified the balance of vegetative and reproductive growth. Also, because peak harvest was $\approx 4$ months after the cessation of enrichment, treatment effects might be expected to be minimized.

From an engineering standpoint, delivery of a $\mathrm{CO}_{2}$-enriched air stream through conventional drip lines functioned well. In the short plot lengths employed, relatively uniform distribution was achieved however, pressure measurements on a 50-m length of line charged by the pumping system showed minimal pressure drop, indicating that the technique is feasible on a larger scale. By injecting an enriched air stream instead of pure $\mathrm{CO}_{2}$, the effects of any nonuniformity of distribution were minimized. The adaptation of this technique to field-scale usage would require a different mechanical scheme than we used to pressurize the system. Also, brands of drip tubing may differ significantly in air flow characteristics, so that careful evaluation would be required.

As performed in this study, $\mathrm{CO}_{2}$ enrichment could be an economically justifiable practice for the production of cucurbits and tomatoes using tunnel culture. Although expenses vary widely among growers in different production areas, preharvest variable costs for these crops under tunnel culture and drip irrigation but without $\mathrm{CO}_{2}$ enrichment, are at least $\$ 2500 /$ ha- 1 ; when fixed costs are added, the total commonly exceeds $\$ 3500 / \mathrm{ha}^{-1}$. Carbon dioxide in bulk containers commonly available in North America cost approximately $\$ 0.08$ to $\$ 0.12 / \mathrm{kg}$, depending on quantity used and proximity to a supply source. At the usage rates in the spring tests, seasonal $\mathrm{CO}_{2}$ costs would approximate $\$ 200$ to $\$ 300 / \mathrm{ha}$. In areas where the weather would permit the use of nonperforated tunnel covers, $\mathrm{CO}_{2}$ usage and expense could be reduced considerably. Carbon dioxide monitors designed for greenhouse use are available for approximately $\$ 1000$. Expense of the delivery system would vary, depending on the level of sophistication and the scale of production. 
The use of this technique would be more difficult to justify economically for strawberry production. Since the use of tunnels is not a common practice for this crop, their considerable cost, plus expenses related to enrichment, would have to be recovered in higher yields or earliness; based on the marginal crop responses we obtained, that is unlikely.

The source of $\mathrm{CO}_{2}$ used in these studies was industrial bottled $\mathrm{CO}_{2}$. This product is captured as a byproduct of industrial processes such as fertilizer manufacturing and food processing. The use of this product in agriculture represents a recycling of $\mathrm{CO}_{2}$ that would otherwise be vented directly to the atmosphere.

In summary, a technique for $\mathrm{CO}_{2}$ enrichment of polyethylene growing tunnels under field conditions was tested. Yields of cucumber, squash, and tomato were significantly increased. The technique, which used existing drip irrigation lines to uniformly distribute applied $\mathrm{CO}_{2}$, appeared to be an economically viable practice. The enrichment used $\mathrm{CO}_{2}$ recycled from unrelated industrial processes and as such was an environmentally sensitive production technique.

\section{Literature Cited}

Arteca, R.N. and B.W. Poovaiah. 1982. Absorption of ${ }^{14} \mathrm{CO}_{2}$ by potato roots and its subsequent translocation. J. Amer. Soc. Hort. Sci. 107:398-401.

Arteca, R.N., B.W. Poovaiah, and O.E. Smith. 1979. Changes in carbon fixation, tuberization and growth induced by $\mathrm{CO}_{2}$ applications to the root zone of potato plants. Science 205:1279-1280.

Arteca, R.N., B.W. Poovaiah, and O.R. Smith. 1980. Use of high performance liquid chromatography for the determination of endogenous hormone levels in Solanum tuberosum L. subjected to carbon dioxide enrichment of the root zone. Plant Physiol. 65:1216-1219.

Baron, J.J. and S.F. Gorski. 1986. Response of eggplant to a root environment enriched with $\mathrm{CO}_{2}$. HortScience 21:495-498.

Calvert, A. and G. Slack. 1975. Effects of carbon dioxide enrichment on growth, development and yield of glasshouse tomatoes, I. Response to controlled concentrations. J. Hort Sci. 50:61-71.

Goldsberry, K.L. 1986. $\mathrm{CO}_{2}$ fertilization of carnations and some other flower crops, p. 117-140. In: H.Z. Enoch and B.A. Kimball (eds.). Carbon dioxide enrichment of greenhouse crops, vol. 2. CRC, Boca Raton, Fla.

Govindarajan, A.G. and B.W. Poovaiah. 1982. Effect of root zone carbon dioxide enrichment on ethylene inhibition of carbon assimilation in potato plants. Physiol. Plant 55:465-469.

Hadley, P. and D.A. Livermore. 1989. The effects of carbon dioxide enrichment under plastic film crop covers on the growth and yield of early, outdoor crisp lettuce. Proc. 21st Natl. Agr. Plastics Congr., Peoria, Ill. p. 301-306.

Kimball, B.A. 1986. Influence of elevated $\mathrm{CO}_{2}$ on crop yield, p. 105116. In: H.Z. Enoch and B.A. Kimball (eds.). Carbon dioxide enrichment of greenhouse crops, vol. 2. CRC, Boca Raton, Fla.

Labanauskas, C.K., L.H. Stolzy, L.J. Klotz, and T.A. De Wolfe. 1971. Soil carbon dioxide and mineral accumulation in citrus seedlings. Plant \& Soil 35:337-346.

Mauney, J.R. and D.L. Hendrix. 1988. Responses of glasshouse grown cotton to irrigation with carbon dioxide-saturated water. Crop Sci. 28:835-838.

Milhet, Y. and C. Costes. 1975. Effects of $\mathrm{CO}_{2}$ nutrition on growth and yield of muskmelon (Cucumis melo L.), eggplant (Solanum melongena L.) and sweet pepper (Capsicum annuum L.). Acta Hort. 51:201-211.

Nakayama, F.S. and D.A. Bucks. 1980. Using subsurface trickle system for carbon dioxide enrichment. Proc. 15th Natl. Agr. Plastics Congr., Tucson, Ariz. p. 13-18.

Peet, M.M. and D.H. Willits. 1987. Greenhouse $\mathrm{CO}_{2}$ enrichment alternatives: effects of increasing concentration or duration of enrichment on cucumber yields. J. Amer. Soc. Hort Sci. 112:236-241.

Slack, G. 1986. $\mathrm{CO}_{2}$ enrichment of vegetable crops, p. 151-166. In: H.Z. Enoch and B.A. Kimball (eds.) Carbon dioxide enrichment of greenhouse crops, vol. 2. CRC, Boca Raton, Fla.

Wittwer, S.C. 1979. Carbon dioxide fertilization of crop plants, p. 310-333. In: U.S. Gupta (ed.). Problems in crop physiology. Okford and IBH Publishing, New Delhi, India.

J. Amer. Soc. Hort. Sci. 116(6):970-973. 1991. 